\title{
Analysis of the Possibility of Limiting the Impact of Ground Vibrations Caused During Demolition of a Towers on Environment
}

\author{
Jan TARGOSZ, Jarosław BEDNARZ, Wojciech LISOWSKI \\ Department of Robotics and Mechatronics \\ AGH University of Science and Technology \\ al. Mickiewicza 30, 30-059 Kraków, Poland; e-mail: jantargosz@interia.pl
}

(received April 25, 2016; accepted June 7, 2016)

\begin{abstract}
Before disassemble and demolition of five granulation towers the authors planned and carried out measurements of the intensity of vibrations induced during the fall of the dismantled components of towers on the ground. The main aim of the study was to determine the maximum permissible weight of falling elements of the towers during the demolition, in terms of ensuring the protection of buildings and equipment located in the vicinity of the works. It was unacceptable to increase the vibration amplitude displacement in each section of measurement on each of the three perpendicular axes by more than $2 \mu \mathrm{m}$ peak-to-peak value and the absolute velocity of RMS of vibration amplitude couldn't be increased by more than $1 \mathrm{~mm} / \mathrm{sec}$ value than the background vibration during the demolition of the towers. Preliminary experimental studies were conducted on a test stand and the measurements were made on the real object. The amplitudes of vibration waves displacement and velocity were recorded on the measurement section in the direction of the protected building. The results of measurements were used to identify the propagation of the shock wave and the effectiveness of the proposed insulation layers.
\end{abstract}

Keywords: ground vibrations; insulation layers; vibrations measurements.

\section{Introduction}

In connection with the planned demolition of five granulation towers, a research problem arose, i.e. determination of the maximum weight of the structural components of the towers and the attached staircases, which might fall onto the ground level without affecting the structure of the nearby building of a manufacturing plant, as well as the rotating machinery that operated continuously inside the building. A method of experimental testing was chosen to solve the stated above problem.

The planned experiments consisted in measurements of the ground vibration induced by impacts of weights of 10, 40, 75 and $100 \mathrm{~kg}$ dropped from a height of about $41 \mathrm{~m}$ (corresponding to the height of demolished towers) on the ground. Due to the expected high sensitivity of the building, as well as of machines operating inside, to vibrations the experiments were planned to be carried out in three following 3 stages:

1) field tests, at a non-operating plant, measurement of vibration induced by the falling element for conditions of a testing ground,

2) measurements of the background vibration level on the foundation of a compressor operating in the building and on the foundation of the building recorded during normal operation of machinery,

3) the field research carried out at the site of the planned demolition comprising measurements of vibrations induced by the falling of the weights of $10,40,75$ and $100 \mathrm{~kg}$ (test weights) on the ground with and without the insulating layers. The measurements were to be made on the building foundation and on the compressor foundations, as well as on its housing.

The distribution of objects located in the research area is presented in Fig. 1. The protected elements of the plant are:

1) $\mathrm{CO}_{2}$ compressor room, which employs a highspeed compressor with a power of $9.2 \mathrm{MW}$ at a distance of $16.45 \mathrm{~m}$ from the granulating towers (D-109),

2) mechanical workshop department of urea at a distance of approx. $8.5 \mathrm{~m}$,

3) storage of urea in bulk, at a distance of approx. $10 \mathrm{~m}(\mathrm{C}-102)$

4) wharf transport of urea in bulk, at a distance of approx. $6.4 \mathrm{~m}$,

5) electrical switch board (D-105/A),

6) stowage (D-105). 


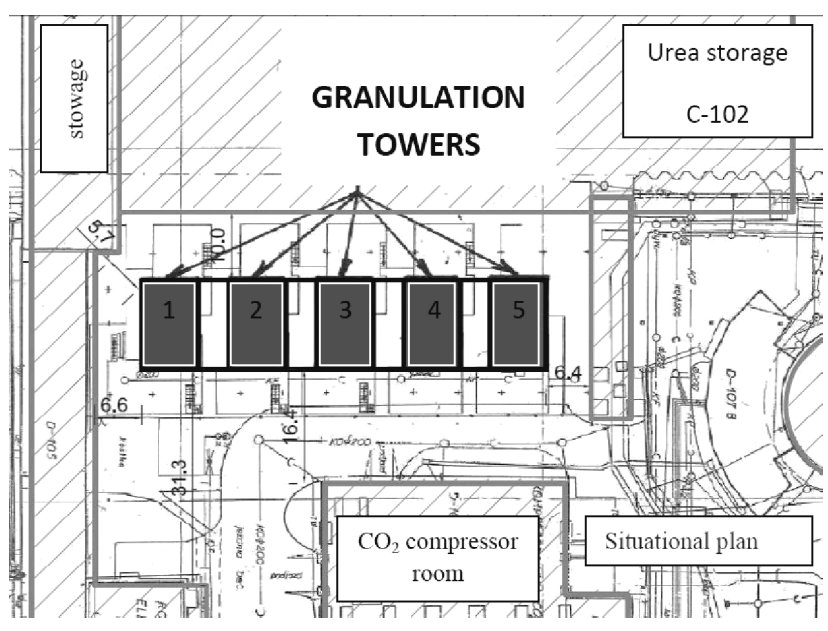

Fig. 1. Plan of the protected objects and objects to demolition.

\section{Measurements of vibrations induced by falling elements at a testing ground}

\subsection{The experiment description}

In order to simulate conditions similar to that present during the actual demolition, the testing ground of the following properties was selected (Fig. 2):

1) a typical industrial facility,

2) giving possibility of excitation of the ground vibration by dropping of different test weights on the ground from a certain height,

3) providing approximately equal distances between the dropping place and a building present at the planned demolition site (Fig. 2).

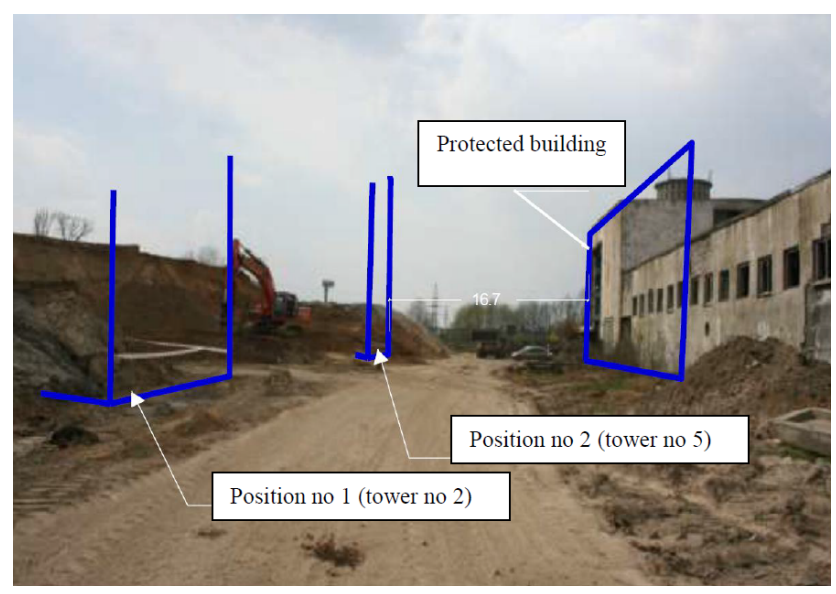

Fig. 2. Overview of the testing ground.

The weights of $10,40,75$ and $100 \mathrm{~kg}$ were raised to a height of about $41 \mathrm{~m}$ and dropped onto the ground covered with a layer of sand of $1 \mathrm{~m}$ thickness. The following locations of the measuring points were used:
1) position 1 - in the ground, $11.7 \mathrm{~m}$ from the vibration excitation area,

2) position 2 - on reinforced concrete column of a building structure, away by $19.7 \mathrm{~m}$ from the vibration excitation area,

3) position 3 - on the building's floor (reinforced concrete), $37.9 \mathrm{~m}$ from the vibration excitation area,

4) position 4 - on a reinforced concrete pillar of the building structure, away by $42.5 \mathrm{~m}$ from the vibration excitation area.

The applied measuring set-up consisted of the multi-channel digital seismometer UVS 1504 (Nitro Consult) and vibration monitoring device Vibraloc $(A B E M)$. The above mentioned devices were used for multi-channel digital recording and monitoring of seismic vibrations (of soil and buiding's structures). They provide tri-axial vibration measurement in the vertical $(z)$ and in two horizontal $(x)$ and $(y)$ directions. Another channel was used to connect a broadband microphone measuring the air pressure of the shock wave (PFU). The seismometers measured vibration velocity with a flat frequency response in the range of $1 \div 1000 \mathrm{~Hz}$ and fully met demands for measuring paraseismic vibration.

In case of the used equipment the event registrations are stored in a file in the recorders' memory. Then, data are sent to a PC via RS 232 for further processing. The systems' operator can program the measuring range basing on the type of meter, the duration of recording and the trigger level. When the monitored signal's amplitude exceeds the chosen trigger level the recording starts and lasts for from $1 \mathrm{~s}$ up to $64 \mathrm{~s}$. Then, the unit returns to standby mode. For the measurements performed on concrete building' structure, concrete elements or bedrock the vibration sensors are braced to the object. In case of the measurement of the ground (subsoil) vibrations the sensors are anchored with three barbs (Fig. 3).
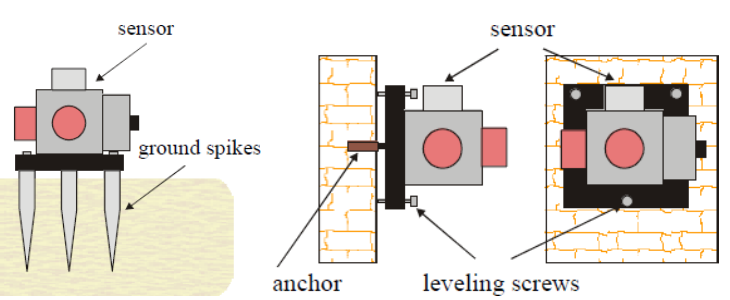

Fig. 3. Technique of mounting the vibration sensor on the foundation of the building and the ground.

\subsection{The results of vibration measurements conducted at the testing ground}

Initially, it was planned to carry out approximately 40 tests consisting in dropping of heavy test weights (10 repetitions for each of the 4 weights) from a level corresponding to the height of the granulation towers 
(Polish standart PN-85/B-02170). Exemplary results of the tests are shown in Fig. 4 for 4 samples measured for the same weight. The recorded signals corresponding to the consequent attempts proved to be highly repeatable as far as the amplitude and frequency of the vibrations excited in the course of measurements were considered. Basing on this consistency it was decided to decrease the number of tests. For further analysis the highest value of vibration velocity recorded amplitude was taken.

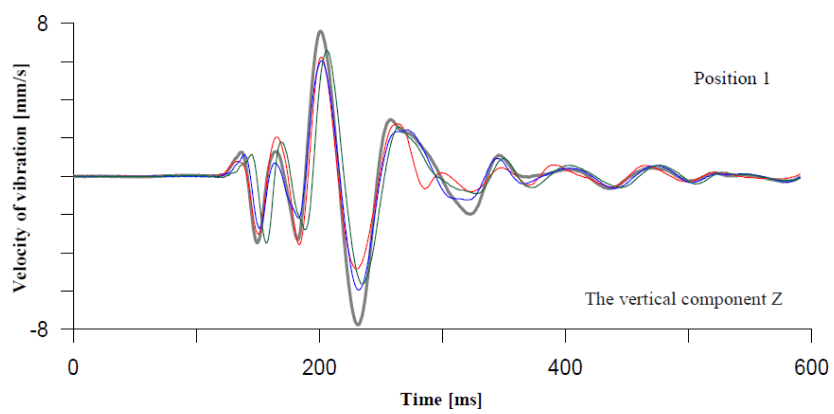

Fig. 4. Comparison of 4 vibration velocity time histories recorded for the same weight dropped at position 1 .

Another important conclusion drawn basing on the comparison of the experimental results was the domination of the vertical component of vibration measured at positions: 2, 3, 4 (sensors attached to the structural elements) located away from the impact area over the horizontal components. Figure 5 presents comparison of the sample time histories of rectangular components of vibration velocity recorded at the position 2 . The results of the considered comparison justified the selection of the vertical component of the measured vibration velocity for the further analysis.

The carried out assessment of the influence of the impact induced transient ground vibration on close building structures was based on analysis of
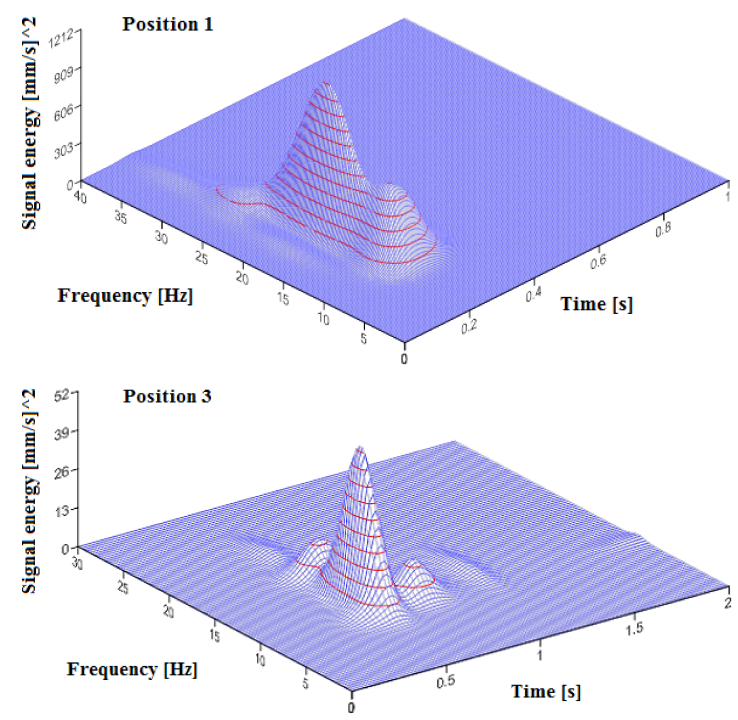

Fig. 6. Time-frequency analysis of the recorded vibrations (the vertical component).

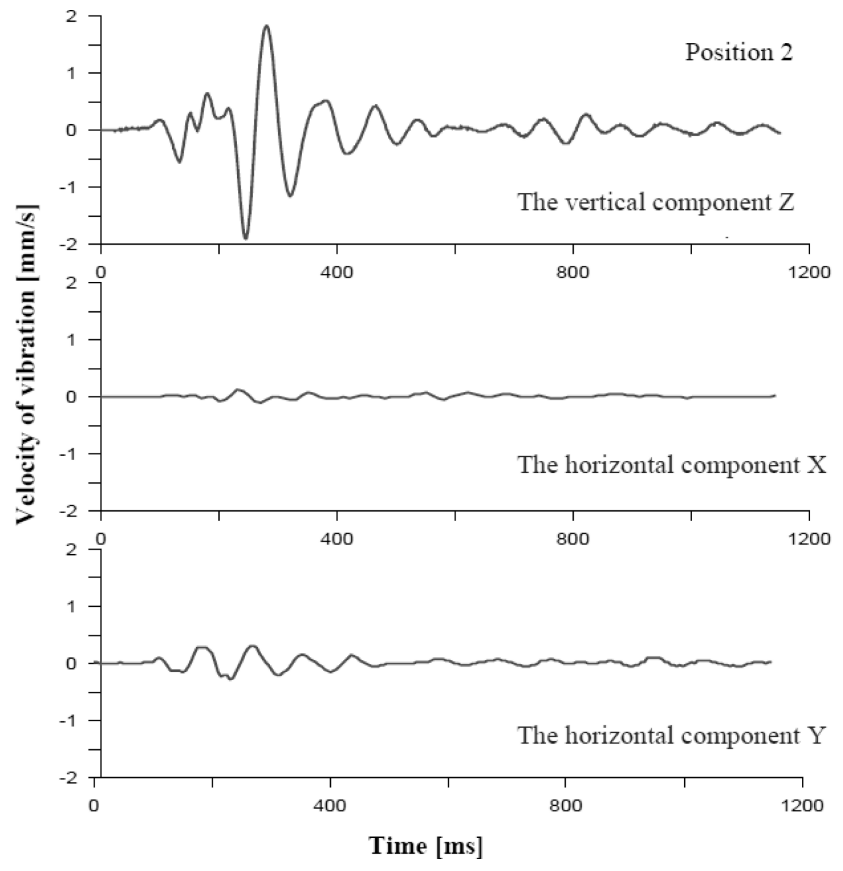

Fig. 5. Recordings of vibration velocity rectangular components - position 2 .

the recorded vibrations' spectra and amplitude variations (Bednarz, 2012; Bednarz, TArgosz, 2011). The recordings of the highest vibration velocity were selected for the analysis. The method of the timefrequency (Gabor transform) analysis was carried out as the most appropriate for the transient signals. It provided isolation of the dominating frequency components of the recorded signals and concurrently it gave base for comparison of the energy of signals measured at the consequent positions for the purpose of determination of the rate of the signals' energy suppression during their propagation in the soil. The exemplary spectrograms are presented in Fig. 6 .
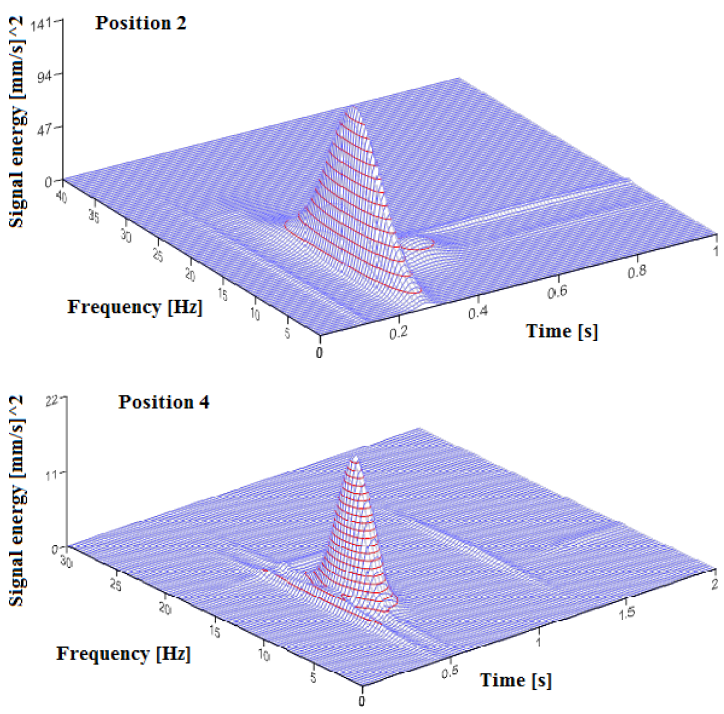
The vibration energy of the signal measured at the position 1 has more than 1,000 units, and the one measured at the position 2 is almost 10 times less (141 units). Finally, the energy corresponding to the position 4 proved to be almost 70 times less.

A decrease in energy is accompanied by the change of the dominant frequency components as shown on histograms of the Gabor atoms presented in Figs. 7, 8, 9 and 10 . The histograms present the vibration velocity signal energy frequency components' content.

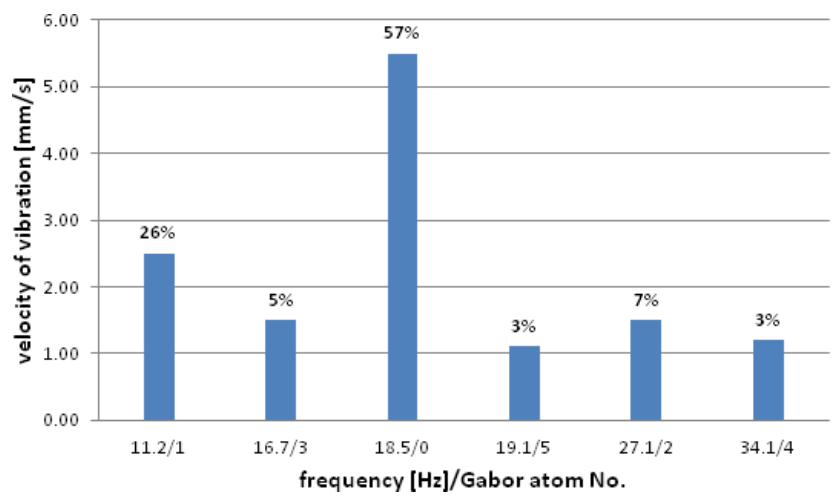

Fig. 7. Time-frequency analysis vibration velocity (position 1).

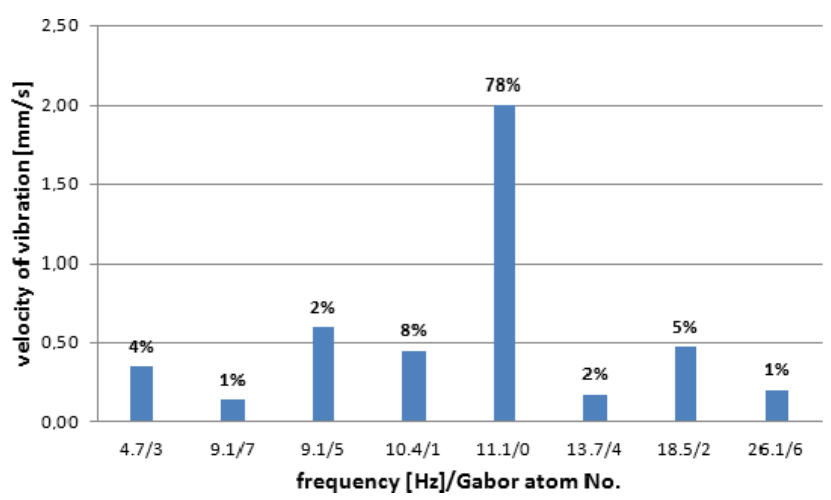

Fig. 8. Time-frequency analysis vibration velocity (position 2).

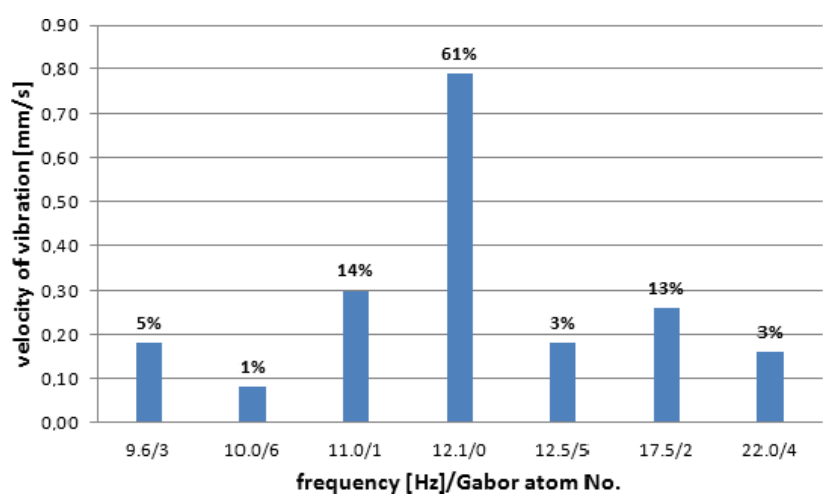

Fig. 9. Time-frequency analysis vibration velocity (position 3).

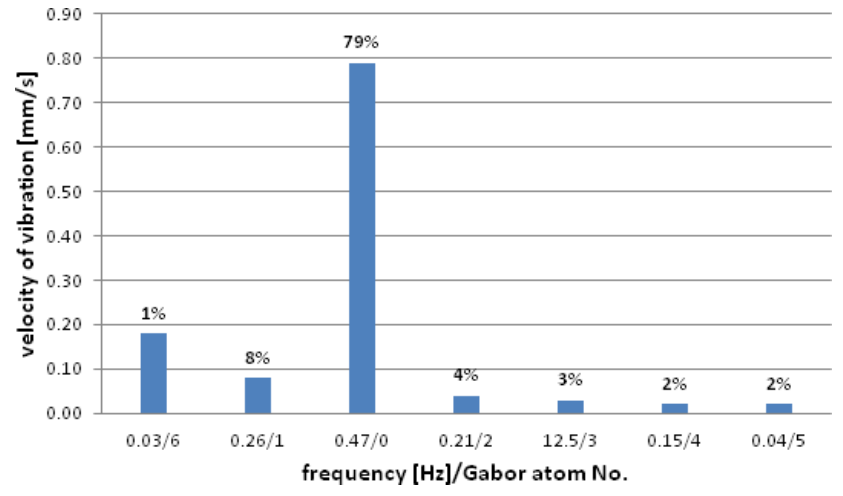

Fig. 10. Time-frequency analysis vibration velocity (position 4).

The results presented in Figs. 7 to 10 show that at all measuring positions the atom with the greatest vibration velocity amplitude carried the highest energy. This meant that the dominant frequency component of the impact induced vibrations had the greatest influence on the surrounding buildings' structure.

The determined Gabor atoms' characteristic for the measuring positions is as follows:

1) position 1 - frequency of $18.5 \mathrm{~Hz}$ with the amplitude of $5.48 \mathrm{~mm} / \mathrm{s}$ and $57 \%$ share in the energy signal,

2) position 2 - frequency of $11.1 \mathrm{~Hz}$ with the amplitude of $2.02 \mathrm{~mm} / \mathrm{s}$ and $78 \%$ share in the energy signal,

3) position 3 - the frequency of $12.1 \mathrm{~Hz}$ with the amplitude of $0.79 \mathrm{~mm} / \mathrm{s}$ and $61 \%$ share in the energy signal,

4) position 4 - the frequency of $11.6 \mathrm{~Hz}$ with the amplitude of $0.48 \mathrm{~mm} / \mathrm{s}$ and $79 \%$ share in the energy of the signal.

The above observations were also confirmed by comparison of spectrograms of the vibration velocity signal's energy resulting from the fall of the weight of $100 \mathrm{~kg}$ and the one of $10 \mathrm{~kg}$. The spectrograms are presented in Fig. 11. The maximum amplitude of the vibration velocity was as much as 5 times less, and the signal energy more than 20 times less for the lighter weight.

For the further analysis of amplitudes of the measuring signals the recordings of the highest amplitude of the vertical vibration velocity component were used.

The first of the conducted analyses aimed at determination of the rate of decrease of the amplitude with respect to the distance from the impact (drop) area. The following form of the realationship was assumed:

$$
u=a \cdot r^{\alpha},
$$

where $u$ - the maximum of vibration velocity amplitude $[\mathrm{mm} / \mathrm{s}], a$ - the ratio, $r$ - the distance from the impact area, $\alpha-$ an exponent. 

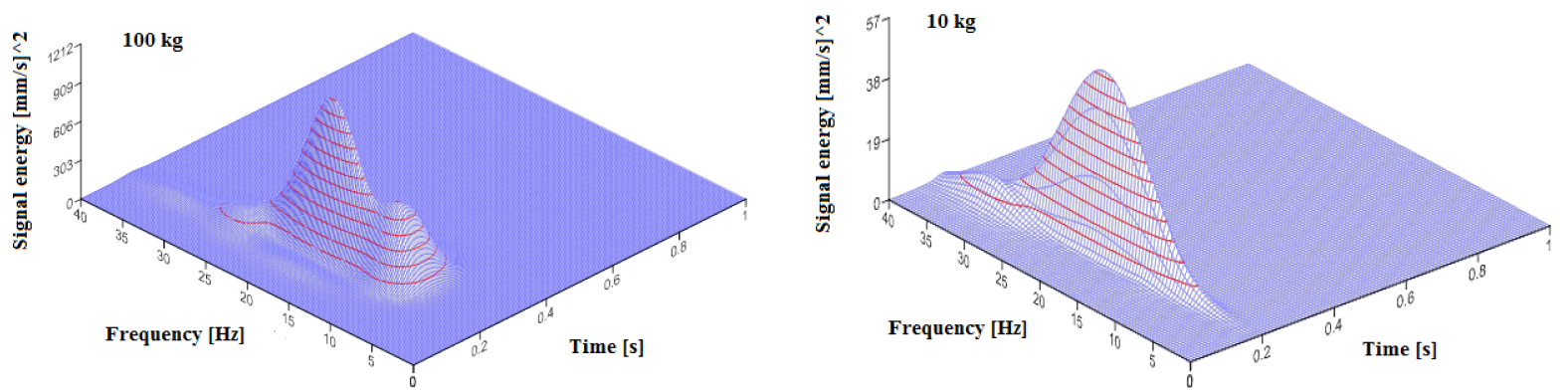

Fig. 11. Time-frequency distribution of the vibration velocity signal's energy (position 1).

As a result of the conducted calculations the following relationships were determined:
1) for the weight of $100 \mathrm{~kg}$
$u=422.8 \cdot r^{-1.697,}$
$u=456.5 \cdot r^{-1.81,}$
$u=157.9 \cdot r^{-1.643}$.
2) for the weight of $75 \mathrm{~kg}$
3) for the weight of $40 \mathrm{~kg}$

The quality of the data corresponding to the weight of $10 \mathrm{~kg}$ was insufficient to build the relationship. The formulated relationships are presented in Fig. 12.

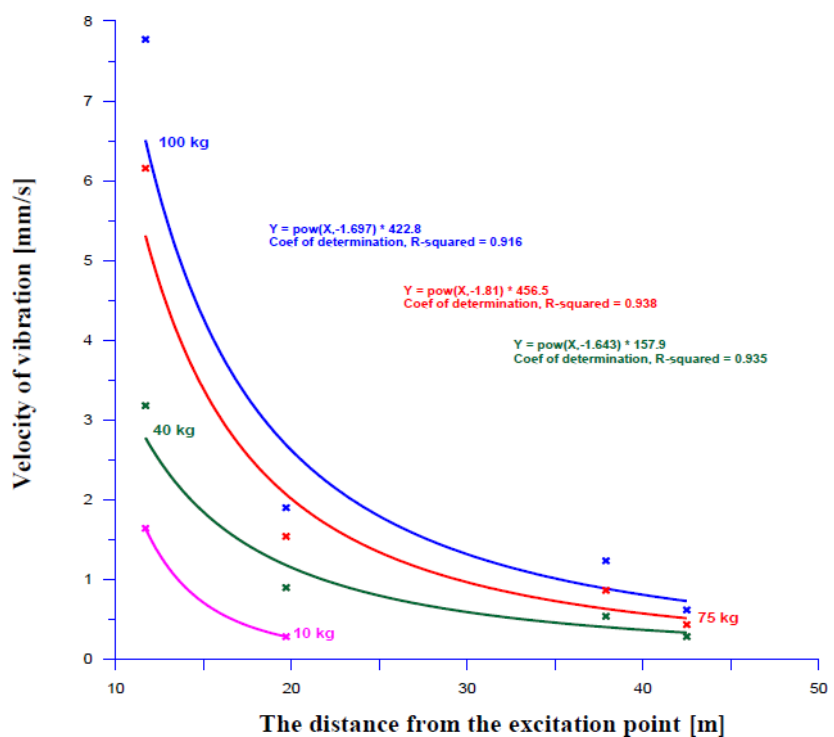

Fig. 12. Relationship between vibration velocity vertical component maximum amplitude and the distance of the measuring point from the impact area for various applied dropped weights.

The second analysis consisted in determination of relationship between the maximum measured vibration velocity amplitude and the mass of the dropped weights for each measuring position. The following structure of the relationship was assumed:

$$
u=b \cdot m^{\beta},
$$

where $u$ - maximum of the vibration velocity vertical component amplitude $[\mathrm{mm} / \mathrm{s}], b$ - factor, $m$ - the mass of the falling weight $[\mathrm{kg}], \beta$ - exponent.
In the result of the approximation procedure the following relationships were formulated:

1) for a distance of $11.7 \mathrm{~m}$

2) for a distance of $19.7 \mathrm{~m}$

3) for a distance of $37.9 \mathrm{~m}$

$$
\begin{aligned}
& u=0.325 \cdot m^{0.671}, \\
& u=0.0417 \cdot m^{0.832}, \\
& u=0.0208 \cdot m^{0.878} \\
& u=0.0135 \cdot m^{0.820} .
\end{aligned}
$$

4) for a distance of $42.5 \mathrm{~m}$

The formulated relationships are presented in Fig. 13.

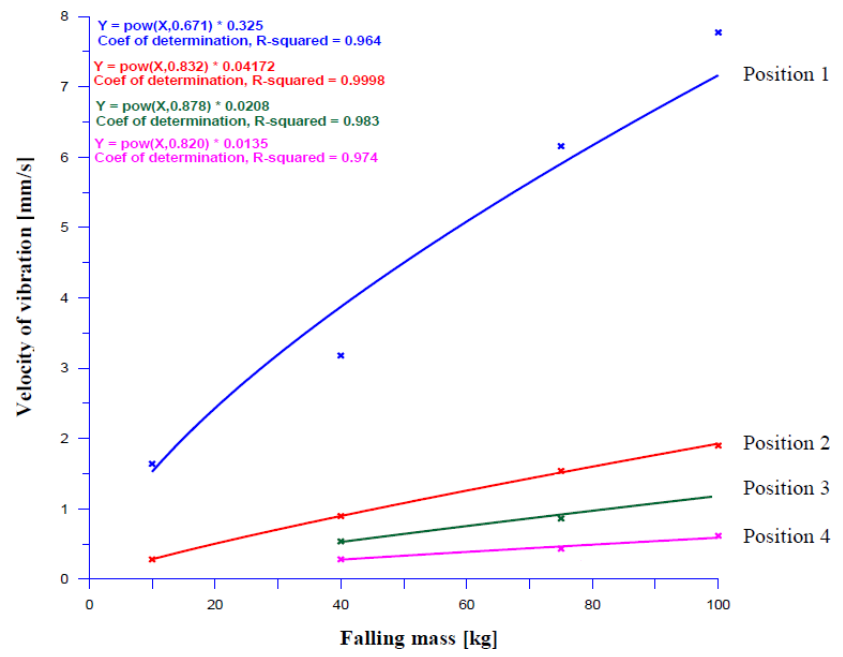

Fig. 13. Relationship between the maximum measured vibration velocity amplitude vertical component and the mass of the dropped weights for each measuring position.

The reported testing results proved that the vibration excited as a result of the impact of weights on the ground was suppressed to the considerable extent on the way from the impact area to the nearby building.

\subsection{Summary of research at the testing ground}

The results of the carried out study confirmed that it was safe for the nearby protected building structure to excite the ground vibration by impact of the falling weights. So the next stage of the investigations, i.e. testing in the conditions prevailing in the area of granulation towers expected to be demolished, could be launched. 


\section{Measurements of the background vibrations during operation of the compressor}

An appropriate assessment of the influence of the ground vibration excited by the impact of the falling substructures during demolition works on a working machine required a prior estimation of the machine's vibration accompanying its normal operation (ŁAcCZKOWSKI, 1974). Additionally, in the considered case, the operation of the compressor was a source of the dominant component of the background vibration for the foundation of the considered building of the manufacturing plant. In the course of the conducted experiment, vibration was measured at two locations at the compressor's foundation:

1) position $\mathrm{F} 1$ - at the lower part of the foundation (approx. $0.3 \mathrm{~m}$ above the foundation base),

2) position $\mathrm{F} 2$ - at the upper part of the foundation (level of the of mounting of the compressor).

The above described locations are shown in Fig. 14.

a)

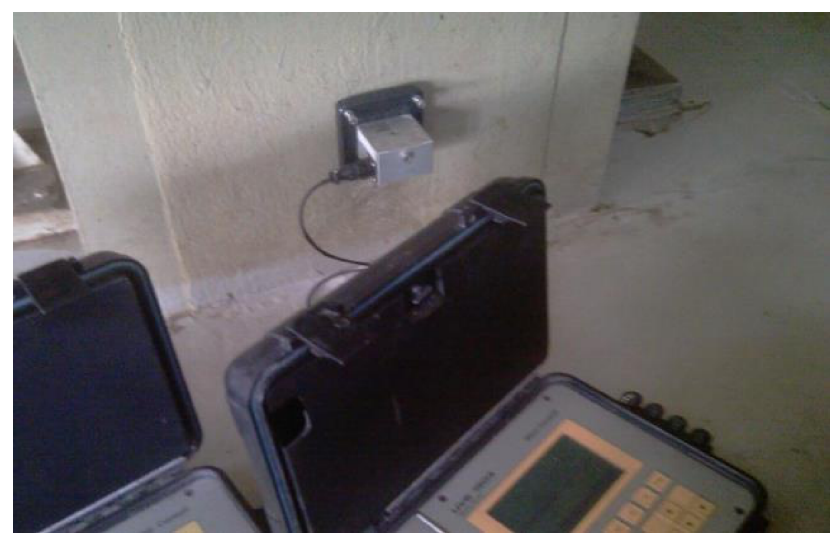

b)

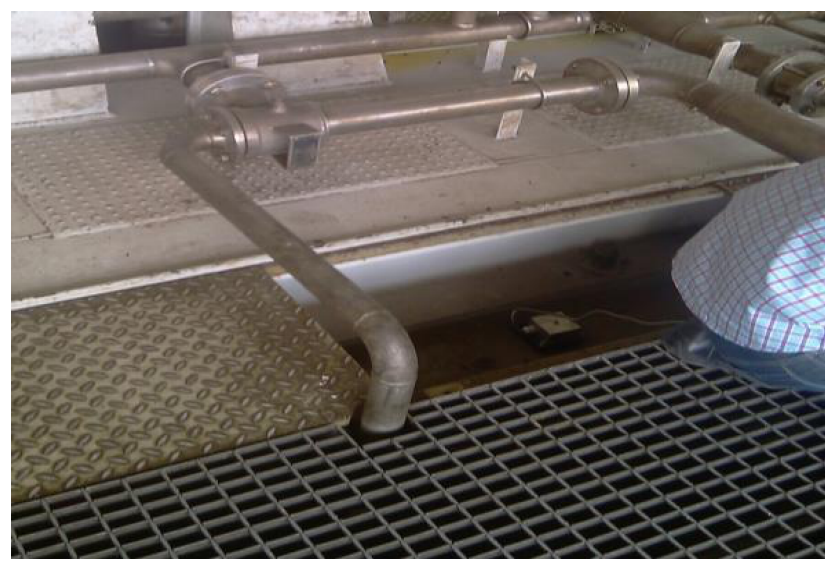

Fig. 14. Locations of the vibration measurement on the foundation of the $\mathrm{CO}_{2}$ compressor: a) position $\mathrm{F} 1$, b) position F2.

Concurrently, the vibration measurement was carried out with use of the standard equipment available at the compressors room. Basing on the analysis of the vibration recorded at the positions shown in Fig. 14 it was determined that the amplitude of the frequency spectrum of the compressor's foundations was dominated by the harmonic components of the rotational speed of the compressor's rotor $(12.5 \mathrm{~Hz}$ and $25 \mathrm{~Hz})$. This is clearly visible on the Wigner-Ville's distribution shown in Fig. 15. The vertical axis of the distribution corresponds to the frequency, the horizontal one to the time, and the colour to the vibration signal's energy of the consequent Gabor atoms (the scale is presented on the right-hand side of the distribution). The map might be applied for determination of the share of energy of the atoms in the total energy of the measured signal. To better illustrate the properties of the distributions, they are presented in Fig. 15 in two versions: as all frequencies creating $95 \%$ of the total signal energy (Fig. 15a), and as the atoms of the highest energy (Fig. 15b).

a)

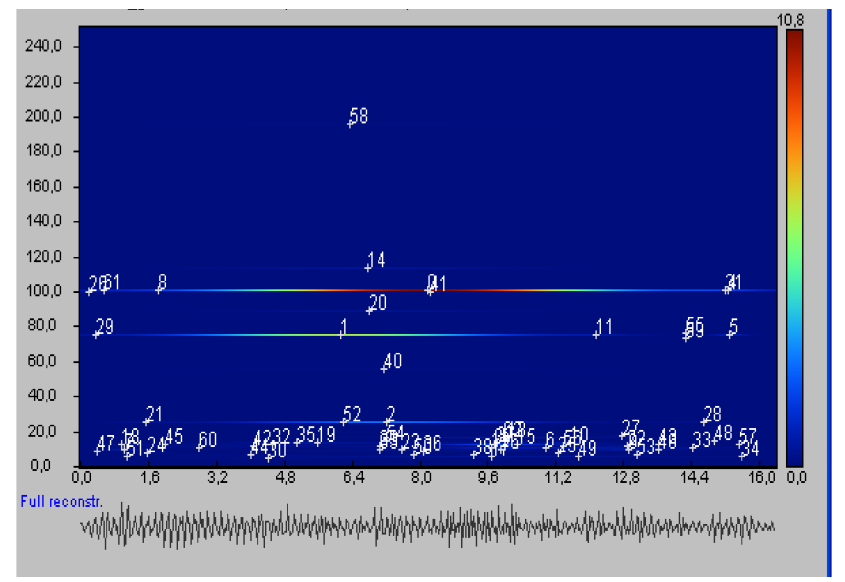

b)

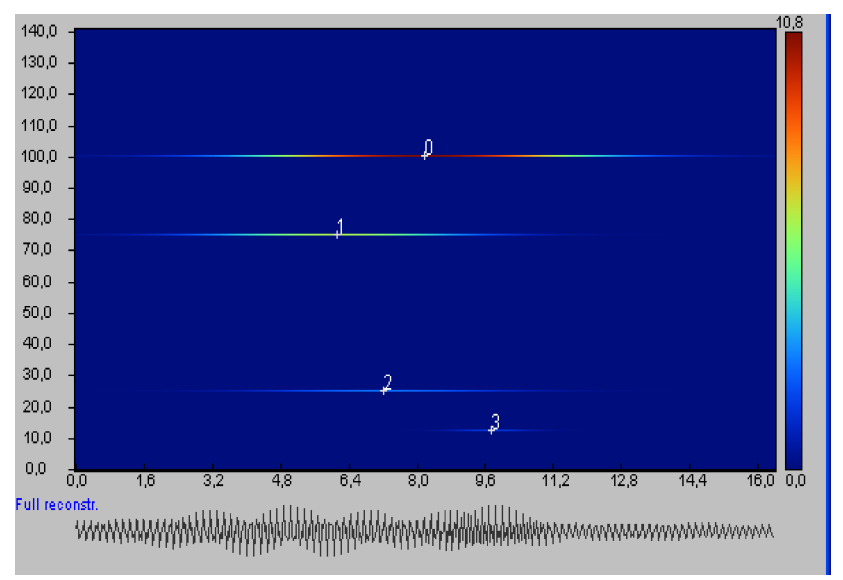

Fig. 15. Wigner-Ville's distributions for vertical component of the compressor's foundation vibrations.

The harmonic components of the rotational speed dominate all the created distributions. For the vertical component apart from $25 \mathrm{~Hz}, 50 \mathrm{~Hz}, 75 \mathrm{~Hz}$ the $100 \mathrm{~Hz}$ 
component is present. The amplitudes of the vibration velocity recorded on the compressor's foundation are limited to:

1) the vertical component $-0.25 \mathrm{~mm} / \mathrm{s}$,

2) the horizontal components $-0.50 \mathrm{~mm} / \mathrm{s}$.

The further analysis of the recorded vibration velocity showed that the maximum amplitudes were reported for the direction corresponding to that of the axis of the compressor's motor shaft. Thus, the axial direction corresponds to the dominating forces created in the compressor and transferred to its foundation (within the limits permitted by the relevant standards).

\section{Measurements of vibrations induced during impact of the test weights falling onto substrate}

In the beginning phase of the experiment the vibrations were induced by the test weights of mass of 10 , 40,75 and $100 \mathrm{~kg}$ falling from a height of $40 \mathrm{~m}$ onto a substrate which was protected by:

1) a layer of straw (cubes made of pressed straw with dimensions of $0.8 \times 1.2 \times 2.4 \mathrm{~m}$ covered with conveyor belts on which the sand layer $0.4 \mathrm{~m}$ was formed),

2) a sand layer (formed as a prism with a height of $1 \mathrm{~m}$ - see Fig. 16),

3) the substrate without any protective layer.

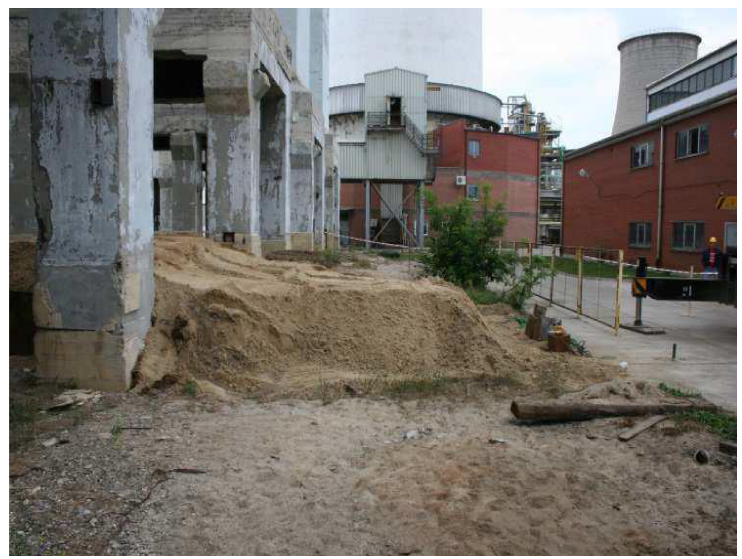

Fig. 16. The damping layer formed as a pile of sand.

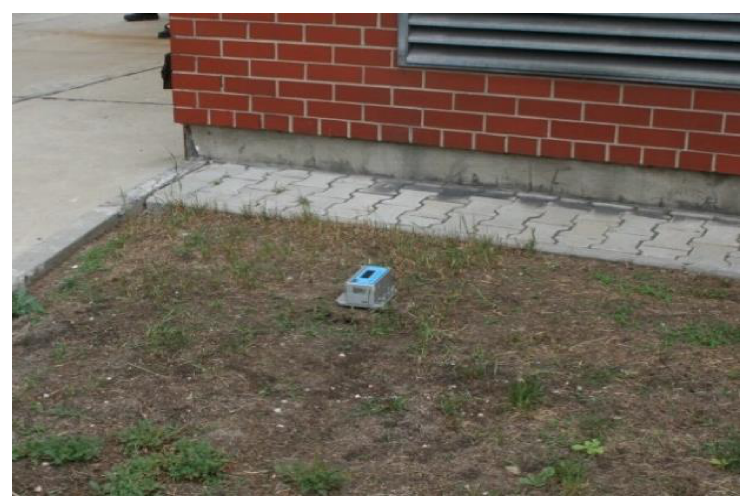

Fig. 17. Location of the position G1.

Measurements were carried out at two positions (F1 and F2) located on the foundation of the compressor (showed in Fig. 14) and on the ground in front of the compressor hall's foundation - the position G1 (showed in Fig. 17).

The background vibrations at the site of the planned demolition works originated from the operational vibrations of the compressor and a set of fans (TARGOsz, 2013). First, the level of the background vibration was determined to set a trigger of the measurement set-up for the registration of the transient vibration (an event) after impact only when its maximum amplitude would exceed the background vibration. This approach was justified by assumption that the substrate vibration excited by the impact of the amplitude level corresponding to the background vibrations amplitude is safe for the structure of the protected building. In the result of such the trigger's setting, data of some conducted tests were not recorded.

First, the test weights were being dropped onto the substrate covered with the protective layers. The forth granulation tower was selected to carry out the test. After analysis of the recorded signals leading to determination of the amplitude of the substrate vibration induced by the impact it was decided to conduct tests for substrate without any protective layers. The obtained results are listed in Table 1.

Analysis of results of the conducted experiments proved that in case of use of the protective layers the amplitudes of the impact excited vibration measured at positions G1, F1 and F2 did not exceed the determined values of amplitudes of the background vibrations.

Table 1. The results of measurements of vibration for the test weight of mass $100 \mathrm{~kg}$ (position G1 - ground under the building; position F1 - lower part of the compressor foundation; position F2 - upper part of the compressor foundation).

\begin{tabular}{|c|c|c|c|c|c|c|c|}
\hline \multirow{2}{*}{$\begin{array}{c}\text { Place } \\
\text { of measurement }\end{array}$} & \multicolumn{3}{|c|}{$\begin{array}{c}\text { Vibration velocity } \\
\text { rectangular components }[\mathrm{mm} / \mathrm{s}]\end{array}$} & \multicolumn{2}{c|}{$\begin{array}{c}\text { Frequency of the maximum } \\
\text { of amplitude [Hz] }\end{array}$} & \multicolumn{2}{c|}{$\begin{array}{c}\text { Velocity vector's } \\
\text { magnitude }[\mathrm{mm} / \mathrm{s}]\end{array}$} \\
\cline { 2 - 8 } & $u_{z}$ & $u_{x}$ & $u_{y}$ & $f_{z}$ & $f_{x}$ & $f_{y}$ & $u_{z x y}$ \\
\hline G1 & 3.73 & 1.70 & 4.21 & 24.7 & 29.0 & 25.7 & 4.723 \\
\hline F1 & 0.42 & 0.22 & 0.13 & 23.3 & 12.5 & 29.7 & 0.429 \\
\hline F2 & 0.54 & 0.53 & 0.32 & 16.1 & 17.9 & 17.5 & 0.759 \\
\hline
\end{tabular}


In case of the test weights dropped directly to the substrate (no protective layers used) higher amplitudes of the vibration velocity were estimated. For the records corresponding to the highest values of amplitudes the time-frequency analysis was carried out. The Wigner-Ville distribution clearly confirmed the lack of significant effects of the impact induced vibrations on the vibrations of the protected building's foundations. Some effect could be noticed only for the case of the direct fall of the weights (no protective layer).

In order to illustrate this effect Fig. 18 presents two Wigner-Ville distributions created for vibration velocity signals measured at positions G1 and F2 for the most unfavourable case of the experiment conditions.

a)

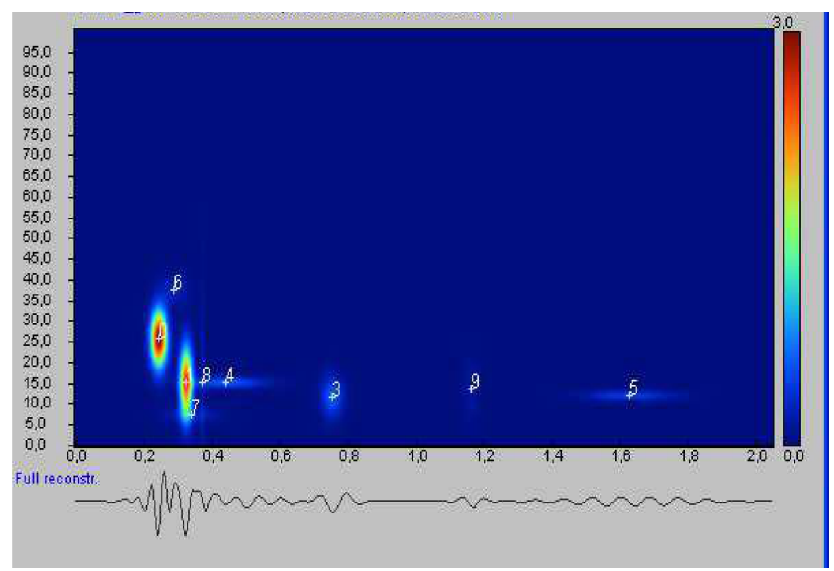

b)

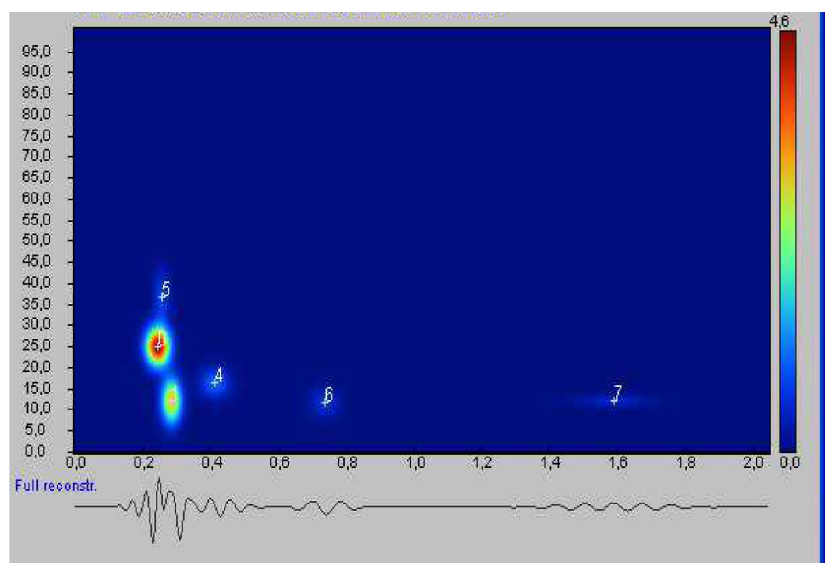

Fig. 18. The Wigner-Ville distribution for the vertical component of the vibration velocity: a) measuring point G1 ground, b) measuring point $\mathrm{F} 2$.

The analysis of the above presented distributions showed that:

1) vibrations generated by the impact of the test weights are significantly attenuated on their way from the impact area to the foundation of the protected building,

2) the evidence of the impact consists in occurrence of two dominating peaks of amplitude in the range of the low frequency at the beginning of the measuring data recording mostly in the vertical component of the vibration velocity recording.

Concurrently to the reported above vibration velocity measurement at the selected points of foundation the measurement of the displacement of the compressor shaft relative to the bearings as well as the shaft velocity of vibration were carried out.

Exemplary results of this measurement are presented in Fig. 19 for the drop of the $100 \mathrm{~kg}$ testing weight.
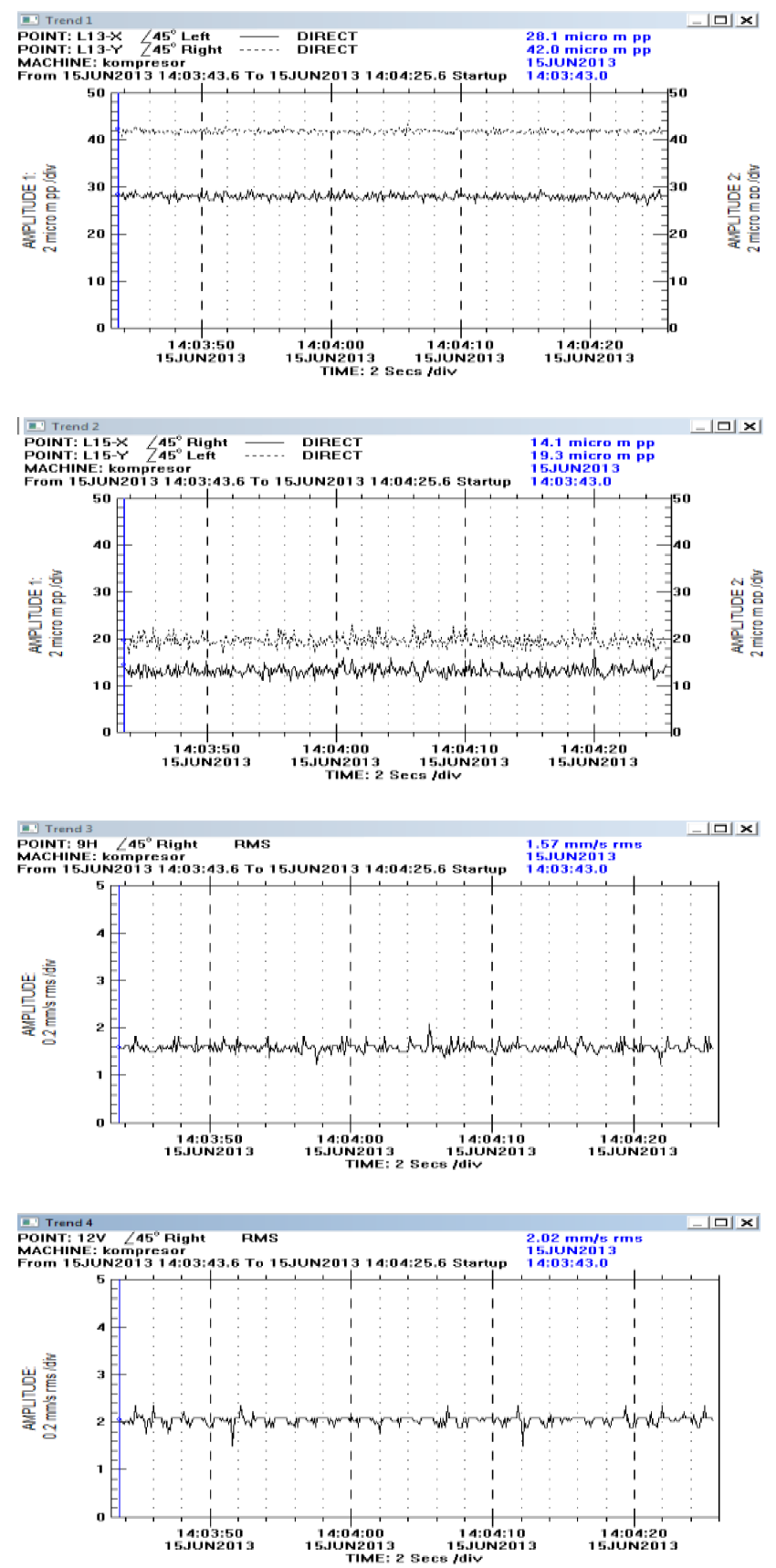

Fig. 19. The results of measurements of relative vibrations displacement and velocity of the compressor shaft containing moment of impact of the weight of $100 \mathrm{~kg}$. 
The results of the considered measurement proved that there was no apparent effect of the impact on the course of measured signals. These results were consistent with the results of the previous parts of testing.

\section{Conclusions}

Basing on the carried out experiments comprising measurements of vibration parameters of the compressor's shaft and foundation it was proved that the ground vibrations excited during impacts of the test weights had no significant influence on the dynamics of the considered machine. There were no disturbances in the operation of the compressor related to the impacts.

Additionally, it was shown that the use of insulation in the form of:

1) a layer of straw covered with conveyor belts and another layer of sand on top,

2) two layers of sand separated by the conveyor belt, 3) a prism of sand,

reduced significantly the vibration caused by impact of heavy weights dropped on the ground.

Finally, it was concluded, that the impacts occurring during the considered demolition works should not affect the level of vibration of the foundation of the protected building as well as of the compressor that operates continuously.
Following the achieved results the demolition of the granulation towers was successfully completed in 2015 . The protective layer composed of two layers of sand separated by the conveyor belts was used.

\section{Acknowledgments}

The research reported in this paper has been financed from the state budget for science.

\section{References}

1. Bednarz J. (2012), Experimental verification of the developed soil model describing the propagation of vibration wave in the ground, Journal of KONES Powertrain and Transport, 19, 3, 31-40.

2. Bednarz J., TArgosz J. (2011), Experimental analysis of propagation of vibration in the ground caused by passing rail vehicles [in Polish], Logistyka, 6, 153-160.

3. ŁAzCzKowski R. (1974), Vibrations of elements of steam turbines [in Polish], Wydawnictwa NaukowoTechniczne, Warszawa.

4. PN-85/B-02170: Rating harmfulness of vibration transmitted by the ground on buildings.

5. Targosz J. (2013), Possibilities to reduce the impact of vibration on the ground engineering structures [in Polish], TTS - Technika Transportu Szynowego, 10, 32033212 . 